\title{
LA COSCIENZA DI ZENO O LA VIDA POR DENTRO: ITINERARIO CONTEMPORÁNEO DE LECTURA
}

\author{
LA COSCIENZA DI ZENO OR LIFE WITHIN: \\ A MODERN JOURNEY IN READING
}

\author{
Juan Carlos de Miguel y Canuto \\ Universitat de València \\ juan.c.miguel@uv.es
}

Fecha de recepción: 18/07/2017

Fecha de aceptación: 07/11/2017

\section{RESUMEN}

Itinerario actualizado de lectura que selecciona las cuestiones críticas que más interés pueden despertar en vísperas del centenario de esta novela de Svevo, texto clave por su modernidad en la historia del género narrativo italiano. Se presta una especial atención a todas las cuestiones estructurales, a los problemas de los niveles narrativos, de las voces que se envuelven y se cruzan, del desdoblamiento entre el yo narrador y el yo narrado, al tiempo, etc. Se atiende asimismo al personaje de Zeno y a los temas principales que jalonan el libro, incluido el psicoanálisis. Se propone la palabra creadora (oral) como un tema digno de profundización en el estudio.

Palabras Clave: Svevo, Zeno, narratología, temas, palabra.

\section{AbSTRACT}

An up-to-date review of readings that address the critical questions of greatest interest in the build-up to the centenary of this novel of Svevo's, a key text for its modernity in the history of Italian narrative. Special attention is paid to questions of structure, problems of narrative moments, voices that enwrap and cross, the doubling of the «I» into narrating and 
narrated forms, time, etc. Emphasis falls also on the character of Zeno and the principal themes that define the book, including psychoanalysis. The (oral) creating word is proposed as an element that would repay further study.

KEY WORDS: Svevo, Zeno, narratology, themes, word.

En pocos años La coscienza de Zeno habrá alcanzado el centenario de su primera publicación. La efectuó su autor, Italo Svevo (1861-1928), a sus expensas, en la editorial boloñesa Cappelli en mayo de 1923. La ocasión se vislumbra propicia para realizar un balance crítico de uno de los hitos de la modernidad narrativa italiana, culminación de la producción mayor del escritor, que incluye Una vita (1892) y Senilità (1898). Svevo, descendiente de una familia hebrea, nació y se crió en la muy mercantil ciudad de Trieste, entonces todavía territorio austrohúngaro, aunque en él dominara la querencia italiana. Desde los tiempos de su formación Svevo fue desarrollando un vínculo con la cultura centroeuropea, en lengua alemana, y con el pensamiento de corte existencial. Su propio pseudónimo, como es conocido, refleja esta dualidad románico-germánica. Su verdadero nombre era Aron Hector Smith.

De La coscienza di Zeno se echa en falta una edición de referencia aceptada por la comunidad de estudiosos y especialistas. No se posee el manuscrito original, solo la edición prínceps, en la que por cuenta de la editorial Cappelli intervino Attilio Ferrara, escritor y corrector; pero subsisten errores sobre cuyas enmiendas difieren los editores del texto. ${ }^{1}$ Es una novela compleja que acumula una cantidad ingente de materiales, en cuya selva es necesario orientarse para su interpretación. La obra surgió, tras larga gestación, en una Europa cambiante y en crisis, inmediatamente posterior a la Primera Guerra Mundial. Encarna la plena emergencia narrativa, en ámbito italiano, de un mundo burgués y mercantil, personificado en un protagonista introspectivo problemático, vulnerable e inseguro. Supone asimismo la introducción del psicoanálisis como fuente temática, útil también para el examen de los personajes y pródigo en recursos narrativos. ${ }^{2}$ Fue en torno a 1910 cuando Svevo empezó a tener familiaridad con esta doctrina/metodología creada pocos años antes — recordémoslo- por un hebreo vienés.

En nuestro recorrido vamos a subrayar los rasgos más contemporáneos de la novela, los que más puedan interesar al lector de hoy. Nos apoyaremos en parte de la bibliografía crítica sobre la materia (la obra y su autor). Dicha bibliografía empezó con, entre otras, las páginas clarividentes de Eugenio Montale, ${ }^{3}$ e incluyó pronto a voces señeras como la de

${ }^{1}$ Cfr., por ejemplo, TELLINI, Gino (2013) Italo Svevo, Roma, Salerno, pp. 141-142. Sigo la ed. de PALMIERI, Nunzia e VITTORINI, Fabio (2004) en I. Svevo, Romanzi e «continuazioni», Milano, Mondadori (Meridiani). En español destaca la edición de RODRÍGUEZ FIERRO, Mercedes (2004) con Introducción de Elisa Martínez Garrido, Madrid, Gredos.

${ }^{2}$ Sin embargo, una verdadera aplicación clínica del psicoanálisis no llega a escenificarse en la novela. No se describirá ni un solo encuentro terapeuta-paciente.

${ }^{3}$ Editadas en MONTALE, Eugenio (1966) Lettere Italo Svevo, con gli scritti di Montale su Svevo, Bari, De Donato. 
Giacomo Debenedetti. ${ }^{4}$ Hoy en día ha llegado a ser desbordante y, a grandes rasgos, ha establecido ya una vulgata hermenéutica, que contiene algunos parámetros dominantes. ${ }^{5}$ No se vincula a Svevo, por ejemplo, a la gran tradición narrativa realista-naturalista del XIX europeo, y se le adscribe, en cambio, a la gran literatura analítica centroeuropea, que llega hasta los años veinte o treinta del siglo xx. Es una corriente integrada por obras que glosan el delirio contemporáneo y el sujeto burgués escindido en su conciencia, con el vacío y la ausencia de una vida verdadera de fondo. Se ha subrayado también la preeminencia del motivo del autoengaño de los personajes svevianos, o su relevante psicologismo. O la idea del mundo como una totalidad fracturada o desarticulada, o la del malestar de la civilización, y la de la escritura como dique de contención del desasosiego del yo, etc. ${ }^{6}$

La obra consta de ocho capítulos no homogéneos, y los primeros ayudan a orientarse en la complejidad del texto, ya que en ellos podemos rastrear desde el principio algunos de sus puntos fuertes, como el cruce de instancias narrativas y su cuestionamiento recíproco, el tipo de proceder diegético que se irá desplegando y los núcleos temáticos que más interesan. En la brevísima Prefazione que abre el libro, nos habla en primera persona un primer narrador, un cierto «Dottor S.» (inicial que incorpora un secretismo, nunca desvelado, excitador de la curiosidad del lector), el cual ha dado a la imprenta por despecho — sin permiso del autor - lo que vamos a leer. Son materiales a los que se alude en términos de «novelle», «autobiografia» y «memorie», con lo que ya queda suscitada y acotada de partida la cuestión genérica, a caballo entre ficción («novelle») y testimonio. El propio terapeuta indujo a su paciente a escribir estos materiales —es, pues, su destinatario interno, su narratario - como una suerte de preparación al psicoanálisis, aunque este ha abandonado una terapia que sigue necesitando. Estamos, pues, ante una escritura propedéutica y ante un doctor que incurre en prácticas éticamente desaconsejables, según él mismo admite. (El «psico-analisi», por otra parte, importa subrayarlo, aparece citado tres veces en una sola página). Se percibe también desde el comienzo una clara ironía en el texto y, de pasada, se nos advierte de que se han acumulado muchas «verità e bugie» en lo que sigue. La Prefazione constituye, pues, una variante, adobada, del viejo recurso narrativo del «manuscrito encontrado», de manzoniana (y cervantina) memoria, cuya función canónica es reforzar el efecto realidad de la historia. Aquí, sin embargo, más bien abre la veda a los desacuerdos y las tensiones entre las voces narrativas estratificadas en el texto y levanta la liebre sobre la fiabilidad del narrador ${ }^{7}$.

\footnotetext{
${ }^{4}$ DEBENEDETTI, Giacomo (1955) «Svevo e Schmitz» en Saggi critici. Seconda serie, Milán, Mondadori e «Italo Svevo» en (1971) Il romanzo del Novecento, Milán, Garzanti.

${ }^{5}$ Entre la bibliografía más reciente e innovadora destaco: CALABRESE, Stefano (2017) La letteratura e la mente. Svevo cognitivista, Milán, Meltemi.

${ }^{6}$ Cfr. ARA, Angelo y MAGRIS, Claudio (2007 [1982]) Trieste. Un'identità di frontiera, Turín, Einaudi, pp. 77-87, passim.

${ }^{7}$ Monica Farnetti es autora de un estudio al respecto, de orientación general, de 2006 (Il manoscritto ritrovato. Storia letteraria di una finzione, Florencia, Società Editrice Fiorentina), y de otro específico («La Prefazione del Dottor S.», en VVAA (1996), I segni e la storia. Studi e testimonianze in onore di Giorgio Luti, Florencia, Le Lettere, pp. 193-206.
} 
El Preambolo, que va a continuación, es también breve, aunque no tanto como la sección anterior. ${ }^{8}$ En él comparece otro narrador, autodiegético, el definitivo, encarnado en el paciente del doctor, que se expresa también en primera persona, y que presta voz al protagonista de la historia. Habla desde un punto de llegada, ya superados los cincuenta años de edad. Su discurso en esta primera entrada es más bien deconstructivo. E incluso contradictorio. Nos transmite su escepticismo sobre el método psicoanalítico, al que, ironizando, no duda en calificar de «noioso» y del que cree que se deriva un cierto caos que, pese a todo, él secunda. El narrador busca proceder con «un po' d'ordine», lo que en el fondo equivale también a reclamar la organización del relato y, para anotar sus sueños, coge «la matita e un pezzo di carta in mano», símbolo evidente de la escritura (del libro) — que transparenta en filigrana al autor-, y advierte que «il presente imperioso risorge e offusca il passato», anticipación de un perspectivismo que impregnará toda la obra, la cual mayoritariamente es una suma de recuerdos a través de un diálogo permanente entre el yo que relata y el yo que recuerda. Así se reconstruye un pasado. En un duermevela, influido por un tratado de psicoanálisis que ha leído, el protagonista ve a un bebé, y en sus comentarios se atisba su pesimismo, su hipocondría, pues le augura la enfermedad y una vida impura de la que en parte él mismo se asqueará. Además es ahora cuando quedamos enterados de que la historia sucede en Trieste, «il personaggio-città», como escribió Montale. ${ }^{9}$

El tercer capítulo, «Il fumo», ya no es un paratexto, como los anteriores. Es una suma de episodios misceláneos, desordenados, avance en este aspecto estructural del resto de capítulos. El protagonista — ahora lo confirma, siguiendo la consigna de su médico— alterna mesa y sillón (diván, podríamos decir) en su intento de dar curso a lo que aquel le ha pedido: reconstruir la historia de su adicción a fumar. Desde casi el primer episodio autobiográfico nos transporta, en su juventud, a la relación con el padre, fumador empedernido, sobre la que profundizará un poco más adelante. Es una relación recreada en un ambiente familiar en el que también cuentan su madre y su hermano. Llevado por su inclinación a fumar, el protagonista — cuyo nombre aún tardará en comparecer ${ }^{10}$ - a fin de proveerse de cigarros, engaña a su progenitor e incluso le sustrae dinero, lo que le suscitará un dominante sentido de culpa y el consiguiente arrepentimiento. Son sentimientos, sobre todo el de culpa, que subyacerán en numerosos episodios futuros.

También asoma en el texto un uso dual del tiempo en el que se abundará, el cruce entre dos tiempos que se interfieren: uno de la historia (pasado) y otro de la narración (presente), pues, por ejemplo, leemos que considera que actuó ante su padre «con una sfacciataggine

\footnotetext{
${ }^{8}$ Como ya señaló Gioanola, «È una specie di risposta indiretta del paziente alla Prefazione del dottor S.», lo que, a mi juicio, siembra dudas sobre su ubicación en la secuencia de los manuscritos que contienen la historia y sobre la conformación final del libro (cfr. las páginas últimas de este artículo referidas al capítulo 8). (GIOANOLA, Elio (1979) Un killer dolcissimo. Indagine psicanalitica sull'opera di Svevo. Génova, Il Melangolo, p. 334).

${ }^{9}$ MONTALE, 1966: 158.

${ }^{10}$ Una rotunda presentación-autoafirmación aparece, aunque no es la primera vez, en el capítulo 5, en un entorno irónico: «Io mi chiamo Zeno», (p. 693). Un poco más adelante leemos el concepto que tiene de sí mismo: «Un uomo intelligente, non brutto, ricco e di buona familia com'ero io» (p. 704).
} 
che ora non avrei e che ancora adesso mi disgusta» (p. 629). ${ }^{11}$ No deja de ser una evidencia del perspectivismo apenas citado y también un ejemplo de la función juzgadora que la voz narradora (yo narrador) ejerce sobre el personaje (yo narrado). Pero dicha dualidad anuncia asimismo una alternancia de tiempos - manifiesta en repetidas catalepsis y prolepsis - que jalonarán todo el libro, lo que constituye un signo del poderío del narrador, que en la construcción de la historia hace y deshace a su antojo. Al protagonista, en su juventud, a la enfermedad de fumar se le añadió otra, antitética: la obsesión por dejar de fumar, que queda sintetizada en la coletilla mil veces pronunciada de «l'ultima sigaretta», que le acompañará de por vida. Más adelante declarará otras, como su miedo a envejecer y a morir ${ }^{12}$. Esta «ultima sigaretta», siempre anunciada y nunca alcanzada, podemos considerarla el primer ítem de la lista de una suerte de lessico famigliare de Zeno, suma de las palabras fetiche (o palabras-objeto) compartidas de su vida. ${ }^{13} \mathrm{La}$ «malattia dell'ultima sigaretta» señala directamente una «mia incapacità» (p. 633) — dice el personaje—, retrata un carácter indeciso, voluble, débil y deja al protagonista con la eterna duda de saber si habría podido llegar a ser «l'uomo ideale e forte» (p. 633) que él mismo se esperaba. Y es que en el campo de batalla de esta historia, como en el de la vida, se lidia también una contienda entre los deseos olímpicos y la realidad ajena a ellos, que no deja de ser la reformulación del viejo conflicto individuo-sociedad. Por otra parte, este último cigarrillo que nunca es tal le sirve al personaje para ejemplificar su concepto del tiempo, que es de carácter cíclico: «il tempo, per me, non è quella cosa impensabile che non s'arresta mai. Da me solo da me ritorna» (p. 635). Sin duda, el cumplimiento mismo del encargo rememorador del médico le ayuda a sostener esta percepción. En el conjunto de la novela, desde un punto de vista de la gramática narrativa, la crítica ha empleado a menudo la expresión «tiempo mixto», tomada del propio Svevo, para aludir a los distintos planos de los hechos que se intersectan en la conciencia del personaje (pasado-presente-futuro). Como explicó Sandro Maxia, lo que se da es «una coscienza attuale che racconta e ordina i fatti svincolandoli dalla cronologia obiettiva e accostandola in modo consono al significato che di volta in volta si vuol fare loro assumere». ${ }^{14}$

Asimismo el problema de la fiabilidad de los recuerdos, de la memoria y sus puntos de apoyo comienza a suscitarse ahora, tempranamente, cuando, a propósito de la convicción

${ }^{11}$ Se puede llegar incluso a perspectivas verdaderamente antagónicas: «Ancora adesso sto ammirando tanta cecità che allora mi pareva chiaroveggenza» (p. 694).

12 Ya presente en Senilità, estos son algunos de los casos en los que se transparenta la figura de Svevo. Otros son su antipatía por el psicoanálisis, el apego al violín, la educación de la propia fémina, determinados sueños reflejados en la novela... Sobre este último aspecto, cfr. Nieves Muñiz Muñiz, «Sogno e delirio in Svevo», en DOLFI, Anna, ed. (1993) Nevrosi e follia nella letteratura moderna. Atti di seminario, Trento, maggio, 1992, Roma, Bulzoni, pp. 315-336.

${ }^{13}$ Veamos otras: durante sus años universitarios Zeno llamaba a su padre con el apodo «vecchio Silva manda denari» y así lo conocían todos; «Povero Corsini!» es la fórmula acordada con Augusta para que le confortara cada vez que le asaltaba el miedo a morir (p. 794); «il signor Cada!» (p. 841) es el apelativo con el que se nombra en la complicidad familiar a Francisco Speier, argentino, el padre de Guido, en referencia al giro itañolo «cada volta», que él cómicamente utiliza (p. 827 e passim); «la busta che io dicevo di buoni propositi», (p. 847 y passim); Copler «restò proverbiale in famiglia e quando i giornali, come avviene spesso annunziano e smentiscono la morte di qualcuno, noi diciamo: "Come il povero Copler"», (p. 868). Sobre la expresión «vecchio Silva» profundiza CAVAGLION, Alberto (2000) Italo Svevo, Milán: Bruno Mondadori, pp. 191-194.

${ }^{14}$ MAXIA, Sandro (1985 [1965]) Lettura di Italo Svevo, Padua: Liviana, p. 106. Un trabajo modélico. 
que ya poseía a los veinte años sobre la enfermedad, Zeno afirma que no sería capaz de recordarla si no fuese porque en aquella época visitó a un doctor especializado en tratamiento eléctrico y se la describió con palabras: «Curioso come si ricordino meglio le parole dette che i sentimenti che non arrivarono a scottere l'aria» (p. 635). Es decir: la verbalización de hechos y sentimientos se presenta como fuente de la memoria, más potente que los hechos y los sentimientos mismos, según se irá comprobando. ${ }^{15} \mathrm{Al}$ problema de la fiabilidad de los recuerdos se añadirá el de la fiabilidad del narrador. En la conversación con el citado médico ya salió a relucir un factor esencial en la vida del personaje y en el desarrollo del libro: «Gli raccontai della mia miseria con le donne» (p. 636). Declara tener cincuenta y siete años y seguir vivamente seducido por las mujeres. Cita, con desprecio, al administrador de sus negocios, Olivi, y cita también su personal afición al violín. Quedamos informados de que es un rentista que vive de las herencias paterna y materna. El tramo final del capítulo, el más extenso, contiene la peripecia del internamiento del protagonista —inicialmente acompañado por su esposa - en una clínica triestina, al que le ha conducido su obsesión fumadora. Es el episodio más cercano de todo el capítulo al presente del relato, en él se da una aproximación máxima entre el tiempo del análisis y el tiempo de la vida, lo que no volverá a ocurrir hasta el capítulo 8 , el último. Asistimos ahora a unos primeros pasos cómicos de Zeno, mezcla de su temperamento oscilante, caprichoso e irónico y de sus obsesiones: el tabaco, las mujeres, la enfermedad y la salud, los celos, etc. No resistirá recluido ni siquiera una noche. Estos cómicos pasos primerizos son un auténtico anticipo de la gran danza que llegará en capítulos sucesivos (aunque corresponda a lapsos temporales anteriores). En definitiva, por ahora, cuando no hemos leído más que una pequeña parte de las páginas de la novela, ya ha sido puesto en cuestión su estatus de verdad, pues se nos ha dicho que el libro se ha publicado a espaldas de su autor y que contiene muchas mentiras; asimismo vemos que se emplea una fuerte ironía ${ }^{16}$ y que hay un trasiego de tiempos unido a un ya evidente narcisismo, siempre mistificador. ${ }^{17}$

Superado este pórtico, entramos en el capítulo 4, asimismo más breve que los inmediatamente siguientes, «La morte di mio padre». Es un capítulo clave, singular, que se distingue de la mayor parte del libro. Más decantado y más impactante. El protagonista informa que la muerte de su padre es «l'avvenimento più importante della mia vita», «una vera grande catastrofe, (...) io, poi, a trent'anni ero un uomo finito» (p. 654). Sucedió el quince de abril de 1890. Se trataba de un hombre «solo e vecchio» (p. 659), pues su esposa

\footnotetext{
15 Se insistirá en la misma idea con posterioridad: «Resta così importante nel mio ricordo la parola del Copler che, quando la ricordo, essa rievoca tutte le sensazioni che vi si associarono, e le cose e le persone» (p. 805).

${ }^{16}$ Un poco más adelante, en un estupendo ejemplo de ironía, dirá el narrador de sí mismo: «Si capisce che è meno malato chi ha poco tempo per esserlo» (p. 796). El narrador sabe distanciarse perfectamente de sí mismo y de sus males: «Fra' due malati [Zeno e Copler] si passò un pomeriggio lietissimo. Si parlò delle loro malattie, ciò che costituisce il massimo svago per un malato (...)», (p. 801). Veamos otro ejemplo excelente: «Passeggiai per una mezz'ora per prendermi il tempo di intendere meglio le cose. Erano tanto chiare che non ci capivo più niente», (p. 895). Señala Fabio Vittorini que la ironía sveviana «distrugge l'univocità e l'autorità del soggetto del discorso [Zeno] e attraverso l'uso serrato della contraddizione e del codice ironico, lo riduce a brandelli» (VITTORINI, Fabio (2003) Guida alla Coscienza di Zeno, Roma, Carocci, p. 120).

17 Una declaración muy categórica llegará más adelante: « Certo il mondo sarebbe meno aspro se molti mi somigliassero», (p. 749). «Un buon cavaliere quale son io», (p. 156) y otras.
} 
había fallecido con anterioridad. El remordimiento - ya señalado- es el sentimiento dominante que al personaje le ha quedado impreso de su propio comportamiento: «rimorso di non averlo amato abbastanza prima che morisse» (p. 659). El capítulo posee muchas digresiones dispersas iniciales y una larga recta final concentrada en la agonía y la rápida muerte. Es una estructura que se repetirá en los principales capítulos sucesivos (dispersión/concentración), que estaba ya presente también en el anterior. La grave enfermedad es la circunstancia que unió al hijo con su padre. Antes la relación había estado marcada por la inconsciencia juvenil, a veces incluso por la provocación y la chanza del vástago ${ }^{18}$. A través del examen de la personalidad del padre, el lector encuentra muchos puntos en común con la del hijo, pese a que este afirme sentirse muy distinto: incapacidad para los negocios, naturaleza mujeriega, apego al tabaco, actitud patriarcal, etc. Paradójicamente, el padre consideraba débil a su hijo («se ne andava convinto della mia insanabile debolezza», p. 669), y el hijo se sentía fuerte comparado con el padre («fra noi due, io rappresentavo la forza e lui la debolezza», p. 655). ${ }^{19}$ Hay un espejarse en la distancia entre padre e hijo, también por razones de edad: «Oggi che scrivo, dopo aver avvicinata l'età di mio padre» (p. 665). Así pues, constatamos, el narrador-personaje no deja de transparentar al autor-escritor. ${ }^{20}$ Por ello surgirá en varios momentos el verbo «confesar» para referirse a cuanto está narrando («debbo confessarlo», p. 664; «qui voglio confessarlo», p. 684, etc.). Confesión, pues, es marbete genérico que debemos añadir a los citados, relatos [novelle], autobiografía y memoria. La confesión no deja de equivaler a un monólogo interior (no flujo de consciencia), el que resuena en los oídos del lector. Un monólogo en el que se disuelve la realidad objetiva en la realidad subjetiva de su consciencia. Una reciente investigación ha evidenciado también un uso muy audaz en La coscienza di Zeno del discurso indirecto libre en primera persona, un mecanismo refinado de la conciencia humana en el que se funden varios tiempos. ${ }^{21}$ Arrepentido de su proceder con su padre, Zeno, repensando en lo sucedido, ahora sí entiende tantas cosas que entonces no fue capaz de entender por su falta de afecto (p. 662).

En la larga recta final del capítulo el hijo relata las horas y los días, intensos, de la agonía de su padre, pasados juntos, velándolo, con la ayuda de un enfermero. Se siente transido de dolor y de culpa. Ha avisado al médico, un doctor de apellido burlesco, Coprosich, que - pese a declarar que no hay esperanza - practica lo que hoy denominaría-

${ }^{18}$ Curiosamente, bastante más adelante leeremos una afimación antitética: «Io sono specialmente sensibile a mancanze di riguardo verso i propri genitori, io, che avevo sopportato con tanta rassegnazione le bizze del mio povero padre», (p. 877).

${ }_{19}$ A esta idea se le ha señalado un origen en Kafka, autor, recuérdese, de la terrible Carta al padre. Lo evoca CAMERINO, Giuseppe Antonio (2002 [1974]) Italo Svevo e la crisi della mitteleuropa, Nápoles, Liguori, p. 199 y ss.

${ }^{20} \mathrm{O}$ mejor, incluso, al analista-narrador-personaje-escritor, pues poco antes hemos podido leer «Adesso che son qui ad analizzarmi, sono colto da un dubbio», (p. 633). La escritura como tal ya había sido aludida recién empezado el capítulo 3: «-Scriva! Scriva! Vedrà come arriverà a vedersi intero», le había espoleado el doctor (p. 628). Y volverá a serlo. «Scrivendo, anzi incidendo sulla carta tali dolorosi ricordi, scopro (...)», p. 669.

${ }^{21}$ GEYER, Paul (2010) «Romanzo critico della coscienza e discorso indiretto libero in prima persona: "La coscienza di Zeno"», Studi italiani, n 2, pp. 69-100. Una de las modalidades estudiadas precisamente es la del discurso indirecto libre en función de monólogo interior. 
mos ensañamiento terapéutico. Zeno llora y rabia, no sabe oponerse eficazmente a la voluntad del médico, lamenta no haber reclamado un segundo juicio clínico, de contraste, y tiene terror a que su padre — que está en un estado de permanente semiinconscienciadespierte y se dé cuenta del momento terminal que está sufriendo. Preferiría que muriese, pero apenas puede manifestarlo. En cambio, debe luchar para cumplir las prescripciones facultativas. El anciano a ratos se muestra muy inquieto y en un determinado momento, Zeno, para impedirle que se levante del lecho, lo sujeta con fuerza y le ordena estarse quieto. El viejo, aterrorizado, obedece, pero al poco se siente morir. El joven le retira de inmediato la presión, pero, ya sentado en la cama, al anciano, airado, solo le da tiempo a alzar el brazo y dejar descender la mano sobre la mejilla de su hijo. A continuación resbala y se precipita al suelo, adonde cae muerto. El lector queda turbado por el patetismo de la escena, que tanto le habrá de doler a Zeno, y por el conjunto de la agonía, eficazmente descrita. Se compadece del atormentado protagonista, que se muestra débil y vulnerable. ${ }^{22}$ Las interpretaciones psicoanalíticas insisten en la centralidad rotunda de la figura paterna en toda la novela. ${ }^{23}$

A pesar de que la escritura de este capítulo al principio está ocasionalmente recorrida por una sutil ironía, aquí no hay compostura ni teatro, predomina una sensación de autenticidad. El lector se siente envuelto en el drama, conmovido, se puede identificar con el personaje, incluso por su fuerza expresiva sospecha que en el argumento pueda subyacer una cierta carga autobiográfica de autor. Más adelante, después de muerto, se volverá a evocar en varias ocasiones al padre, signo del impacto psicológico de lo sucedido en Zeno. ${ }^{24}$ Pero sorprenden un par de confidencias del personaje narrador. La primera de ellas apunta a haber vivido un dolor mistificado. «Purtroppo debbo confessare che al letto di morte di mio padre io albergai nell' animo un grande rancore che stranamente s'avvinse al mio dolore e lo falsificò» (p. 677). Es el rencor al que le mueve el inflexible doctor y su propia falta de coraje para oponerse a él. Pero, sobre todo, nos sorprende leer que «Ora anche quel rimorso è morto insieme a tutti i miei altri sentimenti di cui parlo qui con la freddezza con cui racconterei di avvenimenti toccati ad uno estraneo» (p. 674). El largo tiempo transcurrido desde los hechos vividos al relato de los mismos, pues, ha enfriado los sentimientos del narrador, que no se recata en declararlo. Ambos son toques desrealizadores, que van contra la ilusión de realidad y contra la empatía personaje-lector. Es más, solo unas páginas más adelante, entrando en el capítulo siguiente, el personaje nos descubre su verdadera faz frente a la muerte, a propósito del futuro y prematuro fallecimiento de quien será su suegro, Giovanni Malfenti, al que califica de «mio secondo padre»: «Alla sua tomba come a tutte quelle su cui piansi, il mio dolore fu dedicato anche a quella parte di me stesso che vi era sepolta»

${ }^{22}$ Es llamativo que la categórica definición de «bofetón» para el gesto no aparezca hasta una de las última páginas del libro, cuando a Zeno ya no le quedan pelos en la lengua: «Ma allora io avrei meritato anche lo schiaffo che mio padre volle darmi morendo?» (p. 1059). «La scena terribile del grande schiaffo punitore», escribe Gioanola, op. cit., p. 345.

${ }^{23}$ Maxia, por su parte, señala como la relación entre las generaciones de los padres y los hijos es un gran tema expresionista, y cita los modelos de Kafka, Joyce y Musil (MAXIA, 1985:165).

${ }^{24}$ «Guardai le stelle che avrebbero potuto ancora portare il segno dell'occhiata di addio di mio padre moribondo» (p. 919). «Ne avevo tanto sofferto io alla morte di mio padre» (p. 1033). 
(p. 692). Zeno, pues, revela su psicología profunda, se muestra egoísta y distante, aunque precisamente por ello, en el fondo, más humano. ${ }^{25}$

El extenso capítulo 5, «La storia del mio matrimonio», como su título — de nuevo casi didascálico - indica, contiene el tránsito de Zeno hacia el matrimonio, decisión tomada tras el fallecimiento paterno. Busca mucho más que una esposa, una figura materna que le ayude a superar sus carencias, según declara con perspicacia psicoanalítica: «essa doveva divenire oltre che la mia compagna anche la mia seconda madre che m'avrebbe addotto a una vita intera, virile, di lotta e di vittoria» (p. 705). Durante no pocas páginas asistimos a las diversas especulaciones y piruetas de Zeno, en su acercamiento a la familia del comerciante Malfenti, que le llevarán, tras mucho debatirse, a pedir la mano sucesivamente de tres hermanas: Ada (su favorita), Alberta, y por fin Augusta, la menos agraciada, quien aceptará, tras una primera solicitud formulada por error. Al principio del capítulo se anticipa en buena parte el desenlace, prueba una vez más de que no se busca un desarrollo climático de la trama. ${ }^{26} \mathrm{El}$ final del mismo comprende el casamiento — apenas descrito-, con muchas dudas previas por parte de él. Antes se ha producido un auténtico baile rocambolesco, con pasos adelante y atrás, una suerte de comedia de enredo, celos y neurosis, incluso con una sesión de güija organizada en casa del padre de las cuatro hijas, y con intervención de la madre. ${ }^{27} \mathrm{El}$ conflicto de conciencia queda planteado entre una hermana elegida y no amada (Augusta, su esposa) y otra amada y no seducida (Ada, su cuñada). Zeno durante largo tiempo intentará engañarse a sí mismo al respecto ${ }^{28}$. Más adelante el narrador evocará «quel nostro fidanzamento a quattro», que incluye a su —-futuro— cuñado Guido (p. 1004).

«La moglie e l'amante» es el título anunciador que presenta el aún más extenso capítulo 6. Arranca con las primeras semanas felices de casado de Zeno, solo turbadas a continuación por la conciencia de sus enfermedades. De la mano de un antiguo amigo de universidad, Enrico Copler, un enfermo, conocerá a la joven Carla Gerco, hermosa y pobre, de quien llegará a ser su amante-mentor, en una época tediosa posterior de su confortable vida matrimonial. La relación durará dos años. Antes de iniciarla, sin embargo, atravesará un sinfín de oscilaciones, dudas y arrepentimientos. Y algo parecido le sucederá cuando ya la ha comenzado. Entonces llegará otra danza llena de pasos adelante y atrás, soslayando la conciencia y tropezando y cayendo en el deseo. Entre el arrepentimiento, el abandono y la recaída, peregrinando de una casa a otra y de unos brazos a otros: los de su mujer y los

${ }^{25}$ Un egoísmo de tenor muy semejante se percibe ya en el Alfonso de Una vita ante su madre moribunda, y en el Emilio de Senilità frente a su hermana agónica, Amalia, según apunta TELLINI, 2013:157. Como es sabido, los paralelismos entre las tres obras son abundantes. Nos limitamos a algún breve ejemplo, como este.

${ }^{26}$ Como acabamos de ver, se anticipa la muerte de Giovani Malfenti, pero también se anticipará la de Copler (p. 820). Asimismo el abandono por parte de la amante Carla (p. 850). Y habrá más casos en capítulos posteriores. Está claro que interesan los comportamientos más que los hechos.

${ }^{27}$ El término comedia llegará a utilizarlo el propio Zeno en un par de ocasiones (p. 746). Incluso aludirá a sí mismo en términos de «quel grande attore che in me è andato perduto» (p. 737).

${ }^{28}$ No así Augusta: «Non dimenticherò mai che, pur non amandomi, mi sposasti» (p. 784). El citado perspectivismo se retuerce a propósito del cortejo efectuado a Ada: «M'è difficile raccontare della mia corte ad Ada (...) è stata la più pura avventura della mia vita, anche oggi che son vecchio io la ricordo quale la più turpe» (p. 706). Es otra muestra de los dobleces de Zeno. 
de su amante. Porque la presencia de cada una de ellas estimula y enciende la pasión por la otra. Y es que Zeno goza de bienestar junto a ambas, es casi un hombre con dos amores, que a menudo en su vivencia se retroalimentan. ${ }^{29}$ Muy pronto saltan a la palestra las traiciones, las infidelidades, las mentiras. Zeno, que usa su poder a capricho con su amante, las engaña a ellas y se engaña a sí mismo. Es neuróticamente contradictorio. Pone en pie un teatro de fingimientos. A Carla le da una versión inexacta, aminorada, de su relación de amor con Augusta, lo que le creará un gran cargo de conciencia. Su comportamiento, fuertemente introspectivo, es enfermizo ( Avevo pianto tanto il mio tradimento prima di commetterlo», p. 840). Como enfermizas son algunas de las escenas que organiza. Se suceden varias confesiones de culpabilidad a Augusta, iniciadas y nunca concluidas.

El lector tiene la sensación de asistir a un vaudeville en el que la verdad se extravía y el propio protagonista no sabe bien lo que quiere. Parece literatura de feuilleton. Cuando se celebra un banquete prenupcial en honor de Ada y Guido, sus cuñados, Zeno se excede con el vino y dice y hace inconveniencias. Carla, su mantenida, se empeña en aparecer en público con él, incluso en calidad de esposa. Además, cuando desea conocer a la verdadera cónyuge, Zeno le induce a confusión y, en su lugar, le hace coincidir con su cuñada Ada, en un llamativo juego de superposición entre amante real y amante soñada. También la ruptura con Carla está sujeta a muchas idas y venidas y a contradicciones. Desea y ama a su amante, pero quiere que alguien la aparte de él; y cuando ella decide casarse con un joven maestro de música, de quien Zeno ya sentía celos, herido, reacciona con agresividad y pretende recuperarla. Bajo la superficie de estas agotadoras antinomias late el conflicto entre los deseos más profundos, entre los impulsos inconscientes imparables, y la voluntad consciente del personaje. Amén de la tensión citada entre el yo narrado y el yo narrador. Algunos datos importantes, pero también contradictorios, aparecen muy de pasada hacia el final del capítulo cuando la relación se ha roto. Leemos: «Rimpiango l'acerba fanciulla che fu mia e che io non amai, (...). Era stata un'amante indimenticabile» (p. 881). De pasada también se nos proporciona una clave importante. Por debajo del pesimismo de Zeno late un afán de vitalismo: «Lo stesso desiderio d'intensificare la mia vita, che m'aveva tratto da Carla, m'avrebbe riportato subito da Augusta» (p. 870). El personaje se muestra como un espíritu dual, casi bipolar. Junto al pavonearse de galanterías y logros eróticos, otras noticias se comunican con un extremo laconismo: el fallecimiento de su suegro, el nacimiento de su hija Antonia, etc. El párrafo que cierra el capítulo, un largo retruécano, ejemplifica bien la confusión, la paradoja de Zeno, y el gusto por el alambicamiento de Svevo: «Carla, (...) lei, la dolce, la buona, che aveva persino tentato di amare la donna che io amavo e che non vi era riuscita solo perché io le avevo messo dinanzi un'altra donna e proprio quella che non amavo affatto» (p. 909).

«Storia di una associazione commerciale» es el título del capítulo 7. En él subrepticiamente retoma protagonismo Ada, el viejo amor de Zeno, convertida en su cuñada. Por encima de ella sobresale la figura de Guido Speier, su marido, un joven distinguido y de familia adinerada cuyas andanzas absorben el quehacer de Zeno. El personaje no deja de ser,

${ }^{29}$ Se dan situaciones reflejas como esta: «Feci a Carla una scena d'amore che per la sua falsità e la sua furia somigliava a quella che, preso dal vino, avevo fatto ad Augusta quella notte in vettura» (p. 884-885). 
en algunos aspectos, una contrafigura suya, sobre la que él acabará venciendo. La crítica ha señalado muchos de estos paralelismos y dobletes en la novela. Guido ya ha ocupado no pocas páginas anteriores, en las que ha emergido como el rival que bate al protagonista en el cortejo amoroso, dejándolo desolado, hasta el punto de que incluso tuvo la veleidad de matarlo. Ahora el tiempo ha ido transcurriendo y encontramos a un Zeno más maduro que mantendrá con él unas relaciones más adultas — de hombre a hombre, la primera vez en su vida-, pero inevitablemente ambiguas y contradictorias, pues, aunque le cueste admitirlo, su amor por Ada y su rivalidad y celos hacia Guido no se han extinguido. ${ }^{30}$ De nuevo en este capítulo se repiten ciertos parámetros estructurales ya vistos, como la dispersión inicial y la concentración final de la trama, y la anticipación de la conclusión funesta de la vida de Guido. Si el capítulo 2 se titulaba «La morte di mio padre», este bien habría podido titularse «La morte di mio cognato», pues tal evento sin duda polariza la progresión del argumento y es el centro tácito de la indagación novelesca. Es la cuarta muerte acaecida en la novela, tras la del padre, el suegro y el amigo. ${ }^{31}$ El mundo mercantil triestino también pasa al primer plano, incluyendo sus prácticas y léxico específico. Zeno actúa como una suerte de prudente mentor de Guido en el mundo de los negocios, ocupándose particularmente de la contabilidad; pero este, hombre inmaduro («È un ragazzo e bisogna trattarlo come tale», llegará a decir su esposa, p. 1022), débil y caprichoso, no será un buen educando, apto para mantener con rigor el timón de su empresa. Acabará sucumbiendo, por sus errados negocios, por su falta de disciplina y por su propia incapacidad. Él —y no Zeno-, percibimos ahora, es el verdadero «inepto» de esta novela. Así lo da a entender el proprio narrador, que lo descalifica desde posturas de pensamiento darwinista («Ero tutto salute e forza. (...) Mi paragonavo al povero Guido (...) con la mia vittoria nella stessa lotta nella quale egli era soggiaciuto», p. 1038).

La familia Malfenti se ve implicada casi al completo en la historia y entran en la órbita del narrador-protagonista nuevos personajes secundarios, como Luciano y Carmen, empleados de la empresa, el corredor de bolsa Nilini, y otra serie de figuras menores. Zeno y Guido se convertirán en cabezas de familia, con dos hijos cada uno, hombres adultos que han de hacer frente a sus responsabilidades. Son dos también los años que Zeno pasa junto a su cuñado, los mismos que — como ya hemos visto- duró su relación con Carla, la amante. Aunque no son periodos estrictamente consecutivos, pues el final del segundo y el principio del primero se solapan. La disposición de los capítulos, comprobamos de nuevo, atiende a una índole más temática que cronológica. Siguen abundando las analepsis y las prolepsis. Y el doblete de perspectiva: presente del narrador, pasado del personaje. La trama sentimental y el juego erótico no han desaparecido. Carmen es una mujer de gran belleza que pronto se convertirá en amante de Guido, y Zeno se siente espoleado por ella. Está celoso y envidioso de su cuñado. En su fabular interior, llegará a confesarse que Carmen habría sido el reemplazo idóneo de Carla, y fantasea con haberla compartido con él («Un’ amante in due», p. 935). De alguna manera, en su fuero interno, el cuarteto

\footnotetext{
30 «Zeno si associa a Guido perché, nel profondo, lo odia e perché non è affatto indifferente nei confronti di Ada» (GIOANOLA, 1979: 359).

${ }^{31}$ Cfr. CAMERINO, 2002 capítulo I: «La borghesia, la morte e lo spirito ebraico».
} 
sentimental que forma con su mujer y sus cuñados se transforma en un quinteto al incluir a Carmen. Augusta y Ada, por su parte, se comunican mucho, tejiendo un entramado solo femenino. Las noticias que transmite - o se le escapan- a Zeno tienen repercusión entre ellas; y los canales de comunicación se cruzan. Después de Antonia, nacerá Alfio, un segundo hijo del protagonista, y Ada tras su parto de gemelos enfermará y será internada en varias clínicas, fuera de Trieste. Zeno, muy aprehensivo, incluirá el mal de su pariente en el universo de sus obsesiones patológicas y consultará al respecto libros de medicina. La encontrará muy afeada y deteriorada. La relación de la enferma con su marido será cada vez más conflictiva.

Guido ha recibido una buena dotación dineraria de su padre — que reside en Argentina-, pero desconoce y no tiene interés por el mundo del comercio. Con actitud poco responsable irá de error en error y posteriormente, ya con grandes pérdidas acumuladas, se jugará el capital en la bolsa. El resultado final será ruinoso. Zeno querrá ayudarle, pero el viento no sopla a favor. Guido intentará suicidarse, para presionar a Ada a que colabore en enjugar sus deudas. Habrá un primer simulacro que consigue sus fines, pero en el segundo un encadenamiento fatal de adversidades lo conducirá a una muerte en verdad indeseada. Circunstancia que solo conocerá Zeno, el cual — negociando en bolsa- conseguirá resarcir a la familia una parte sustanciosa de las pérdidas. Entretenido en estas gestiones llegará tarde y se equivocará de entierro. Es el lapsus más llamativo de toda la novela, pero no el único. La viuda quedará sacudida por la tragedia y, tras trastornar sus relaciones con Zeno, partirá en barco hacia Argentina con sus hijos. Guido, con su comportamiento, pone en el disparadero de la ambivalencia a Zeno y hace (re)surgir sus contradicciones. Piensa unas cosas y hace otras. Mentirá en no pocas ocasiones, para evitar conflictos, a Augusta, a Ada, y a Guido mismo, con quien — no obstante — se verá obligado a mantener algunas fuertes discusiones. La culpa seguirá siendo predominante en su sentir. Comprobará la complejidad de las relaciones profundas que a veces, a tenor de la contraparte, no pueden ser reconducidas a un único sendero. Así, por su cuñado experimenta, «disdegno», «disprezzo», «nausea» (p. 982). Pero también, como digo, culpa: «Nel momento in cui Guido avrebbe avuto bisogno del mio affetto, non lo trovò» (p. 1012), además de compasión. Para Gioanola —no se olvide-Zeno es el «killer dolcissimo», capaz de combinar «il massimo di distruttività e il massimo d'innocenza». ${ }^{32}$ Algo semejante sucede en relación con Ada. El trato entre ambos tiene vaivenes; pero si una cosa queda clara, a pesar de sus palabras contrarias, es que Zeno nunca ha dejado de esperar su amor. En la conclusión del capítulo él, significativamente, expresa que a ojos de ella «ero di nuovo non l'unico uomo della famiglia, ma il migliore» (p. 1039).

«Psico-analisis» es el muy relevante epílogo recapitulador, relativamente breve. En él se remodela el andamiaje narrativo y se concluye la historia con un giro inesperado. Ahora definitivamente el personaje (el Zeno «joven», de tiempos pasados) converge y se identifica con el narrador (el Zeno «mayor», de un tiempo actual). Las nuevas páginas, dinámicas, resolutorias, se proponen como un manuscrito añadido, posterior en un año a las que les preceden, y se presentan con la forma de un diario, forma testimonial, íntima, de narración.

32 GIOANOLA, 1979: 359. 
Está fechado (de mayo 1915 a marzo 1916) y dividido en cuatro bloques, dotados cada uno de ellos de identidad argumental propia. En principio, no forman parte de las «memorias» en poder del Dottor S. anunciadas al inicio del libro, pues corresponden ya a una etapa de ruptura entre paciente y doctor. Se produce, pues, ahora una suerte de cierre ideal del marco narrativo abierto en la Prefazione y el Preambolo, vuelve a transparentarse en la superficie el autor, latente en el texto, revestido de escritor, que se superpone e impone sobre el mero narrador autobiográfico. Narrador que ha venido prevaleciendo hasta casi hacer olvidar al lector la matriz terapéutica de todo el largo relato, confeccionado para un destinatario interno. Muy a última hora, un señuelo de la trama servirá de hipótesis tácita que garantice idealmente la fusión de este apéndice final con el resto en un todo —el original del libro que el lector tiene en sus manos-. Se nos hace saber que el doctor, desde Suiza, ha reclamado al paciente cuanto hubiera ulteriormente anotado, y este se lo concede, justificándose en un párrafo de tenor performativo: «Giacché possiede tutte le mie confessioni, si tenga anche queste poche pagine e ancora qualcuna che volentieri aggiungo a sua edificazione» (p. 1081).

Subyace una irónica carga de profundidad, una rectificación de las páginas anteriores, ya que el «autor»-personaje, Zeno, al principio del capítulo manifiesta que se siente más enfermo que nunca y canta a pleno pulmón la palinodia del psicoanálisis. Un psicoanálisis a cuyas sesiones ha renunciado, porque cree que nada le ha solucionado, mientras que el terapeuta, diagnosticándole un mero complejo de Edipo, lo ha dado por curado. Por ello, trae a colación al doctor —-mucho más que en el resto del libro-, se burla de él y lo caricaturiza, formulando una crítica diletantesca del psicoanálisis, con profusión de ejemplos. De la misma manera, vuelve con la mente a su manuscrito en poder del Doctor S., hace algunas consideraciones al respecto, y se refugia en la escritura, amparo en el que permanecerá («Io mi rimetto ai miei cari fogli», p. 1048. «Sono qui solo con la penna in mano», p. 1049, «A tutt'oggi che scrivo», p. 1076). Son relevantes también en este capítulo la insistencia en la distinción lengua-dialecto ${ }^{33}$, y el papel irrenunciable de la mujer en su vida, personificada, ahora que es viejo, en el intento de conquista de la rústica Teresina.

Por otra parte, han pasado los años, estamos a la altura de la Gran Guerra, contienda en la que —como sabemos- Italia acabó entrando en 1915. Zeno se ve sorprendido por este hecho durante un paseo matutino por el campo, tropas imperiales le impiden regresar a casa. Está en dificultades. En las páginas finales — fechadas el 24 de marzo de 1916se siente viejo, pero está lucidísimo. Clarividente. Se ha quedado solo en Trieste, ciudad abandonada por casi toda su familia y por el administrador de sus bienes. Ha aprovechado la coyuntura bélica, favorable, para realizar beneficiosas compras patrimoniales y ha salido triunfador. Por una vez en su vida se ha visto felizmente dueño de sus propios negocios $;$ sin culpa ni remordimiento! Se siente fuerte, con salud. Se ha dado cuenta, por otra parte, de que la vida y la enfermedad son indisociables. Se siente curado y, por tanto, lo está. A estas alturas de la historia, llama la atención la lectura de este párrafo: «Il dottore, quando avrà ricevuta quest'ultima parte del mio manoscritto, dovrebbe restituirmelo tutto. Lo rifarei con chiarezza vera perché come potevo intendere la mia vita quando non ne co-

\footnotetext{
${ }^{33}$ Cfr. ALBERTOCCHI, Giovanni (2008) «I sogni di Zeno», Quaderns d'Italià, n. 13, pp. 71-80.
} 
noscevo quest'ultimo periodo». Si la escritura es una forma vicaria de vida, está claro que la pretensión de Zeno no es otra que rehacer, retrospectivamente, su vida desde la salud, lo que nos devuelve al vínculo escritura-vida en su plenitud de implicaciones. ${ }^{34}$ Por otra parte, ahora quizás podemos entender mejor ese concepto circular del tiempo citado en el capítulo 3. Pero a este primer cierre, en positivo, le sucede otro segundo, una coda final. La novela concluye con un conocido alegato crítico visionario, un tanto arcano en su significado, que descoloca al lector al tiempo que lo incluye, pues el narrador usa la primera persona del plural. El clima bélico hace consciente a Zeno de las perversiones del ser humano, y pronostica, fantaseando, una futura «catástrofe inaudita» planetaria. El conflicto individual, parece, se ha resuelto; pero ha desembocado en un conflicto colectivo, universal.

\section{ALGUNAS CONCLUSIONES}

La cosciencia di Zeno es la conciencia y, sobre todo, la consciencia que el personaje tiene de sus actos, sus decisiones, su vida. Esto sería el genitivo subjetivo, pero también cabe interpretar el título como un genitivo objetivo: ${ }^{35}$ Zeno (etimológicamente, extranje$r o)^{36}$, a su vez, está preso de su con(s)ciencia. Es «un uomo che si lascia vivere», como escribió magistralmente Montale ${ }^{37}$, y que carece de un verdadero objetivo en la vida. Esta es la epopeya que vive el personaje. Una epopeya urbana y burguesa, en la que el hombre, ser animal, lejos de las cavernas, lejos del contacto con la naturaleza, satisface su instintiva sed de aventura en el ámbito de lo privado, en la gestión de sus sentimientos, de sus relaciones sociofamiliares y de su sexualidad. Los límites los pone la sociedad a través precisamente de dicha con(s)ciencia, trabajosamente inculcada en el ser y es ahí donde surge el conflicto que es la vida de cada individuo. ${ }^{38}$ En el relato autobiográfico que hemos leído, por otra parte, lo interpretativo predomina, a menudo polémicamente, sobre lo factual, porque no hay objetividad sino con(s)ciencia y memoria individual de los hechos.

La novela despliega una arquitectura moderna empezando ya desde su base narratológica. Interesa lo que el libro contiene de cavilación sobre el género narrativo, sobre la novela, que constituye ya de por sí un marco de decameroniana memoria. Según avanzamos

\footnotetext{
34 «L'esercizio di recupero memoriale imposto dal dottor S. (...) si è liberato di qualsiasi forma di subordinazione alla psicanalisi ed è diventato un esercizio autonomo di riscrittura della propria vita, che finisce per presentarsi come l'unico strumento necessario e sufficiente per produrre una guarizione, $o$, più precisamente, il convincimento di essere guarito» (STASI, Beatrice (2005) Svevo, Bolonia, Il Mulino, p. 106).

35 Eduardo Saccone analizó a fondo todas las posibilidades interpretativas del título, que no son pocas (SACCONE, Eduardo (1973) Commento a «Zeno». Saggio sul testo di Svevo. Bolonia, Il Mulino, pp. 46-52. También aborda la polisemia de la voz «coscienza», recurriendo incluso a las variadas traducciones del título habidas (ibídem).

${ }^{36}$ Cfr. la ed. que estamos siguiendo del texto, p. 1585 nota. Pero también, según otros, el nombre recuerda al filósofo presocrático Zenon de Elea (v. gr., STASI, 2005: 124).

37 MONTALE, 1966: 167.

38 «Non è la società il vero problema di Svevo, ma l'uomo, e, per essere più esatti, la coscienza dell'uomo. (...) Il tipo umano [dolorosamente scisso] che lo ossessionava (...) è l'uomo che rifiuta un sistema di certezze morali che gli ripugna ma non ne possiede un altro da contrapporli» (MAXIA, 1985: 96).
} 
en las páginas, el narrador (personaje que escribe) exhibe cada vez más músculo, su poderío, su libertad de administración de la historia. Pero en verdad, desde el principio, se nos ha introducido en un dédalo de instancias que se cruzan y que están apuntando a la no fiabilidad, según hemos visto, todo lo cual exigirá un lector desconfiado, «malicioso». ${ }^{39}$ Este conjunto de factores, incluido el particular uso del tiempo, le concederá a La coscienza di Zeno carta de naturaleza de novela moderna del siglo xx. Un género que ha hecho de su ser técnico el eje de su progreso contemporáneo. Es una novela, una ficción contaminada con la confesión, la autobiografía, el libro de memorias, el diario, entre cuyas subespecificaciones genéricas oscila; todo lo cual refuerza, si cabe, su modernidad. Pero también es una novela de formación cuyo protagonista — que no héroe- alcanza la madurez tras un accidentado y enriquecedor recorrido vital, suma de amores, temores, negocios, nacimientos y muertes.

Los temas desarrollados ya los hemos ido desgranando: el psicoanálisis, la enfermedad, la familia burguesa judeo-cristiana, las relaciones sociales, el amor, el erotismo, el comercio, la infancia, la vejez, la muerte. Pero todos tamizados por la ironía y la parodia (es la ambigüedad de la que hablan algunos críticos). Con esa actitud puede lograrse la empatía con el lector, que difícilmente se podrá identificar con un personaje histriónico, lleno de dobleces, contradicciones y paradojas, pero sí con su actitud intelectual ante la vida (ecos de las lecturas de su autor: Nietzsche, Schopenhauer, Darwin y otros), pues este libro aporta una compleja visión del mundo. Zeno, su peripecia sentimental y vital, está en el centro de todo y sería posible inventariar una gramática de sus principios comportamentales, muchos de los cuales se formulan explícitamente, como una suerte de destilado de su sabiduría vital $^{40}$. Con todo, encuentro más relevante para nuestro tiempo toda la reflexión contenida en la novela en torno a la lengua y la palabra (dicha), ya subrayada por Raimondi. ${ }^{41}$ Ambas se relacionan con la mentira; y la segunda, específicamente, este es el nudo, con la creación de eventos y mundos. Como la escritura. Es un filón crítico para explorar más.

${ }^{39}$ Cfr. SAVELLI, Guido (1998) L'ambiguità necessaria. Zeno e il suo lettore, Milán, Angeli. Stasi, en su síntesis crítica, efectúa una lectura muy completa de la novela, tan inteligente como minuciosa, en la que recoge todos los indicios para una interpretación a contracorriente en la cual se desmontan y cuestionan las versiones «oficiales» de los principales episodios, dadas por Zeno narrador, y desvela interpretaciones alternativas, cuando no opuestas. (STASI, 2005: capítulo V, 101-136).

${ }^{40}$ Por ejemplo: «È [solo] alla vendita che si giudica l'accortezza dell'acquisto» (p. 790). «Appresi che la bellezza femminile simula dei sentimenti coi quali nulla a ha vedere» (p. 810), etc.

41 RAIMONDI, Ezio (2005) «Svevo e la malattia della parola», en Da Dante a Montale. Studi di filologia e critica letteraria in onore di Emilio Pasquini. Bolonia, Gedit, pp. 725-731. Incluido en Id (2009) Il senso della letteratura, Bolonia, Il Mulino, capítulo X, p. 242-248. 